\title{
Contenus gastriques du lama et du mouton
}

\author{
C Dardillat, R Baumont, JP Jouany
}

INRA, station de recherche sur la nutrition des herbivores, 63122 Saint-Genès-Champanelle, France

Un Camélidé comme le lama possède 3 réservoirs gastriques. Les compartiments 1 et 2 homologues du rumen et du réseau présentent des cellules glandulaires qui sécrètent un mucus riche en bicarbonate. Le compartiment 3, tubulaire, ne sécrète de l'acide chlorydrique que dans son quart distal (Langer, 1988). Pour préciser les caractéristiques physiques des contenus, une canule en caoutchouc a été placée sur le $1^{\text {er }} \mathrm{com}$ partiment chez 3 lamas : son diamètre de $90 \mathrm{~mm}$ permet l'introduction aisée du bras et offre la possibilité de vider complètement les réservoirs 1 et 2 sans aucune gêne pour l'animal. Des mesures avant et $2 \mathrm{~h}$ après un repas ad libitum de foin de prairie naturelle sont effectuées sur les lamas ainsi que sur 3 moutons munis de canules amovibles de $75 \mathrm{~mm}$. Le pH a été mesuré in situ au moyen d'une électrode gastrique de $2 \mathrm{~mm}$ de diamètre introduite manuellement dans différents sites à partir de la canule.

Le pH œesophagien en amont du cardia chez le lama et le mouton s'élève de 7,2-7,5 à 7,9-8 lors de l'arrivée d'un bol de salive. La sonde peut être introduite dans le feuillet et même la caillette du mouton ( $\mathrm{pH} 1,5$ à 2), en revanche chez le lama l'introduction sur plus de $30 \mathrm{~cm}$ dans le compartiment 3 ne permet pas d'atteindre la zone distale fortement acide et le pH est le même que dans le feuillet. La différence de $\mathrm{pH}$ entre le sac dorsal et ventral ruminal est plus grande chez le lama que chez le mouton en particulier deux $h$ après le repas, ce qui traduirait un brassage moins efficace résultant probablement du contenu plus $\mathrm{sec}$ et plus consistant chez le lama. Le compartiment 2, riche en cellules glandulaires, a le $\mathrm{pH}$ le plus alcalin. Le pH élevé du contenu obtenu après vidage chez le lama ( $\mathrm{pH}$ moyen) et qui ne diminue pas après le repas suggère un rôle important des sécrétions gastriques et salivaires qui tamponnent plus efficacement les contenus. Le poids frais du contenu des 2 premiers estomacs (tableau I) et la quantité ingérée rapporté au poids de l'animal $(0,019$ vs 0,0165$)$ sont $15 \%$ plus élevés chez les moutons que chez les lamas. En revanche, le poids sec de contenu rapporté à la quantité ingérée est supérieure chez le lama ce qui pourrait traduire un temps de rétention allongé.

Langer $P$ (1988) The Mammalia Herbivore Stomach Comparative Anatomy Function and Evolution. (Gustav Fisher, ed)

Tableau I. Comparaison des contenus gastriques chez 3 lamas et 3 moutons (2 répétitions par animal).

\begin{tabular}{|c|c|c|c|c|c|}
\hline \multirow{2}{*}{\multicolumn{2}{|c|}{ Contenus des compartiments $1+2$}} & \multicolumn{2}{|c|}{ Lamas (PV $98 \mathrm{~kg}$ ) } & \multicolumn{2}{|c|}{ Moutons (PV $68 \mathrm{~kg}$ ) } \\
\hline & & 0 & $2 h$ & 0 & $2 h$ \\
\hline $\begin{array}{l}\text { Réseau + rumen } \\
\text { ou } 1+2 \\
\text { pH } 1 \text { ou rumen do } \\
\text { pH } 1 \text { ou rumen ve } \\
\text { pH } 2 \text { ou réseau } \\
\text { pH } 3 \text { ou feuillet }\end{array}$ & $\begin{array}{l}\text { Poids frais/kg } \\
\text { Matières sèche (\%) } \\
\text { Poids sec/Ql } \\
\mathrm{pH} \text { moyen } \\
\text { rsal } \\
\text { ntral }\end{array}$ & $\begin{array}{r}13.1 \pm 0.5 \\
12.2 \pm 0.3 \\
1.0 \pm 0.1 \\
7.0 \pm 0.1 \\
6.9 \pm 0.2 \\
7.0 \pm 0.1 \\
7.2 \pm 0.1 \\
6.9 \pm 0.1\end{array}$ & $\begin{array}{r}15.3 \pm 1.6 \\
13.0 \pm 0.9 \\
1.2 \pm 0.2 \\
7.0 \pm 0.1 \\
6.5 \pm 0.4 \\
6.8 \pm 0.1 \\
6.9 \pm 0.1 \\
6.7 \pm 0.3\end{array}$ & $\begin{array}{r}10.3 \pm 2.2 \\
10.5 \pm 1.2 \\
0.8 \pm 0.2 \\
6.8 \pm 0.1 \\
6.75 \pm 0.1 \\
6.8 \pm 0.1 \\
6.9 \pm 0.1 \\
6.7 \pm 0.3\end{array}$ & $\begin{array}{r}11.1 \pm 1.6 \\
11.9 \pm 1.3 \\
1.1 \pm 0.2 \\
6.6 \pm 0.1 \\
6.5 \pm 0.1 \\
6.5 \pm 0.2 \\
6.7 \pm 0.1 \\
6.7 \pm 0.2\end{array}$ \\
\hline
\end{tabular}

